\title{
Competitive advantage in SMEs: effect of supply chain management practices, logistics capabilities and logistics integration in a developing country
}

\author{
Benjamin Tukamuhabwa, Henry Mutebi and Rhona Kyomuhendo \\ Procurement and Logistics Management, Business School, Makerere University, \\ Kampala, Uganda
}

\begin{abstract}
Purpose - The purpose of this paper is to explore the relationship between supply chain management practices, logistics capabilities, logistics integration and competitive advantage of Small and Medium Enterprises (SMEs) in a developing country.

Design/methodology/approach - Using a structured questionnaire survey, cross-sectional data collected from 204 SMEs in Kampala - Uganda were analysed using exploratory and confirmatory factor analysis, and Structural Equation Modelling (SEM) using AMOS version 26 to validate the theorised relationships.

Findings - The study findings revealed that both supply chain management practices and logistics integration are positively and significantly associated with competitive advantage. Also, both supply chain management practices and logistics capabilities are positively and significantly associated with logistics integration. Additionally, the authors found that logistics integration partially mediates in the relationships between supply chain management practices and competitive advantage, and logistics capabilities and competitive advantage. Conclusively, the three independent variables collectively account for $11 \%$ variance in competitive advantage of SMEs.

Originality/value - Given the general observation that SMEs are fundamental to socio-economic development, yet resource constrained, this study uses Resource-based and dynamic capabilities theoretical perspectives to provide an empirical understanding of the supply chain and logistics resources and capabilities necessary for building competitive advantage of SMEs in the context of a developing economy.
\end{abstract}

Keywords Supply chain management practices, Logistics capabilities, Logistics integration,

Competitive advantage, SMEs

Paper type Research paper

\section{Introduction}

In both developed and developing economies, Small and Medium Enterprises (SMEs) are fundamental to socio-economic growth and development for they constitute a significant part of global supply chains. For example, SMEs constitute about $99 \%$ of UK industry (SullivanTaylor and Branicki, 2011). In Uganda, SMEs and micro enterprises constitute about $90 \%$ of private sector industry (National survey of small businesses in Uganda, 2015). Although SMEs can be categorised variously in different economies, developing countries such as

(C) Benjamin Tukamuhabwa, Henry Mutebi and Rhona Kyomuhendo. Published in Journal of Business and Socio-economic Development. Published by Emerald Publishing Limited. This article is published under the Creative Commons Attribution (CC BY 4.0) licence. Anyone may reproduce, distribute, translate and create derivative works of this article (for both commercial and non-commercial purposes), subject to full attribution to the original publication and authors. The full terms of this licence may be seen at http://creativecommons.org/licences/by/4.0/legalcode

The authors acknowledge the almighty God for their lives and the tireless work done by the editors and reviewers. This article was funded by the authors.

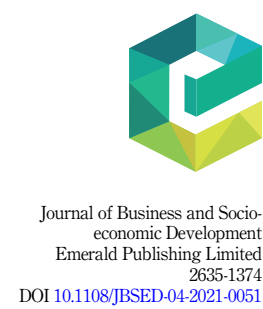


Uganda categorise SMEs based on the number of employees, capital investment and annual sales turnover (Uganda Bureau of Statistics report, 2003). In Uganda, the Ministry of Finance, Planning and Economic Development (MFPED) defines a small enterprise as one employing a minimum of 5 people and a maximum of 50 . A medium enterprise employs between 50 and 100 people (MFPED report, 2008). Besides their crucial role, SMEs are more disadvantaged than large firms and this compromises their competitive advantage (Wedawatta et al., 2010; Thun et al., 2011). Yet, it has been recently emphasised that, in order to achieve industrial growth and economic development, the competitiveness and sustainability of SMEs deserve significant attention (Arsawan et al., 2020).

The extant literature indicates that SMEs have various supply chain deficiencies that affect their competitiveness. For example, compared to large firms, SMEs are understood to be more vulnerable to supply chain disruptions (Thun et al., 2011; Ali and Gölgeci, 2019), lack sufficient resources (Thun et al., 2011; Arsawan et al., 2020), do not adequately prepare for supply chain disruptions (e.g. Wedawatta et al., 2010) and encounter several operational constraints that retard their competitive advantage. In Uganda, SMEs are less competitive as depicted in the observation that many of them collapse within their first five years and only 5-10\% survive and reach maturity (Private Sector Foundation Uganda, 2006). Moreover, the increased failure rate of SMEs has been pronounced in both developed and developing countries (Arsawan et al., 2020). SMEs in Uganda suffer from late deliveries, poor quality products or delivery failures, which reflect poor supply chain performance and reduced competitive advantage (Eyaa and Ntayi, 2010). Recent empirical literature has underlined the role of logistics and supply chain management (SCM) practices and capabilities in creating firms' competitive advantage (McGinnis et al., 2010; Aziz et al., 2020; Keskin et al., 2021). SCM practices such as strategic supplier partnership, customer relationships, information sharing and postponement have been earmarked as vital for building competitive advantage (Li et al., 2006; Afraz et al., 2021; Huo et al., 2021; Migdadi, 2021).

Previous scholarly evidence suggests that firms' competitive advantage can be achieved by developing unique logistics practices and capabilities (Zhao et al., 2001; Mentzer et al., 2004; Gligor and Holcomb, 2012, 2014a, b; Sandberg and Abrahamsson, 2011; Day et al., 2015). According to reports (e.g. World Bank report, 2017; JICA report, 2017), the efficiency and effectiveness of logistics have an impact on competitive priorities such as cost, availability, smooth movement of goods and services and meeting customer expectations. However, reports have shown that firms in Uganda have registered unsatisfactory logistics performance in the form of delayed deliveries, data invisibility and inadequate customer service delivery, which hamper their competitiveness (World Bank report, 2017; Langley and Capegmini, 2017). There are several dimensions of logistics capabilities suggested in the literature. However, a considerable stream of research consent that logistics capabilities necessary for creating and enhancing competitive advantage include demand management capabilities, supply management capabilities and information management capabilities (Mentzer et al., 2004; Gligor and Holcomb, 2012, 2014a, b).

Furthermore, it is argued that the ability to integrate logistics capabilities across the supply chain can be considered as a dynamic capability (Gligor and Holcomb, 2012, 2014a, b). Hence, from the dynamic capabilities perspective of the resource-based view, the ability to integrate logistics capabilities across the supply chain is an important source of competitive advantage (Gligor and Holcomb, 2012; Chang et al., 2021). Logistics integration, which can be external to the organisation or intra-organisational (Rodrigues et al., 2004; Li et al., 2006; Gimenez, 2006; Paulraj and Chen, 2007; Gligor and Holcomb, 2012; Mellat-Parast and Spillan, 2014) can enable the firm to integrate, build, and reconfigure internal and external competences to address rapidly changing environments (Teece et al., 1997). Scholars have suggested different forms in which logistics and SCM related competitive advantage could manifest. However, based on the scrutiny of several dimensions used in the previous studies, 
Li et al. (2006) concluded that the dimensions of competitive advantage that can be gained from SCM practices are: price/cost, quality, delivery dependability, product innovation, and time to market. Other antecedents of competitive advantage underlined in the recent supply chain research include supply chain integration (Mellat-Parast and Spillan, 2014), innovative capabilities and supply chain risk management capabilities (Kwak et al., 2018). These studies have observed the need for more empirical studies on potential enhancers of competitive advantage. In response, this study investigates the extent to which SCM practices, logistics capabilities and logistics integration contribute to SMEs' competitive advantage.

The rest of this paper is organised as follows: Section 2 contains the theoretical review and research hypotheses while Section 3 contains the methodology used. Section 4 follows with the empirical results while Section 5 discusses the results before summary and conclusions are provided in Section 6.

\section{Theoretical review and hypotheses development}

The Resource-based view (RBV) and related dynamic capabilities perspective lay foundation for this study. The RBV postulates that a firm's own resources create superior performance, which then translates into competitive advantage (Barney, 1991; Sanders et al., 2011). According to Barney (1991), firm resources include assets, capabilities, organisational processes, firm attributes, information and knowledge among others. The RBV can be used to assess the development of logistics and SCM practices and their impact on firm competitiveness (Mellat-Parast and Spillan, 2014). Indeed Arsawan et al. (2020) underlined that SMEs' inability to manage resources has aggravated their failure in both developed and developing countries. According to the RBV, resources are linked to capabilities and capabilities to performance (Gligor and Holcomb, 2012). Dynamic capabilities refer to "the firm's ability to integrate, build, and reconfigure internal and external competences to address rapidly changing environments" (Teece et al., 1997). Firms which successfully use resources to develop capabilities can potentially build more competitive advantage resulting in higher performance than those in which resource-capability link does not exist (Barney, 1991).

Prior research has investigated SCM practices and capabilities from the RBV (e.g. Gligor and Holcomb, 2012; Brandon-Jones et al., 2014; Kwak et al., 2018). Related to this, Gligor and Holcomb (2012) argue that the ability to integrate logistics capabilities across the supply chain can be considered a dynamic capability. Logistics capabilities have been underlined as a source of firms' competitive advantage (Zhao et al., 2001; Mentzer et al., 2004; Sandberg and Abrahamsson, 2011; Gligor and Holcomb, 2012, 2014a; Day et al., 2015). This is because logistics capabilities can be used to adapt, integrate and reconfigure resources, organisational skills and functional competencies to achieve superior performance (Morash et al., 1996; Stank and Lackey, 1997; Mentzer et al., 2004). Gligor and Holcomb (2014b) add that within the $\mathrm{RBV}$, the integration of logistics capabilities can be considered a source of competitive advantage that results from idiosyncratic inter-firm linkages or knowledge-sharing routines.

\subsection{Supply chain management (SCM) practices and competitive advantage}

Competitive advantage refers to the extent to which an organisation is able to build a defensible position over competitors (Porter, 1985; McGinnis and Vallopra, 1999). Porter (1985) suggested that firms can pursue either a cost leadership or a differentiation strategy to achieve competitive advantage. Later, several authors suggested different dimensions of competitive advantage. For example, Koufteros et al. (1997) suggested five dimensions: competitive pricing, premium pricing, value-to-customer quality, dependable delivery, and production innovation. Li et al. (2006) observed that the most commonly used dimensions of
Competitive advantage in SMEs 
competitive advantage are: price/cost, quality, delivery dependability, product innovation and time to market. SCM practices refer to a set of activities undertaken by a firm to promote effective management of its supply chain (Li et al., 2006; Koh et al., 2007). Different scholars have compiled varying lists of SCM practices. These include: purchasing, quality, and customer relations (Tan et al., 1998), supply chain integration, information sharing, customer service management, and JIT capability (Tan et al., 2002). Min and Mentzer (2004) include agreed vision and goals, information sharing, risk and reward sharing, cooperation, process integration, long-term relationship and agreed supply chain leadership. Li et al. (2006) based on prior literature to develop five distinctive dimensions of SCM practices that arguably represent both upstream and downstream portions of the supply chain. These practices include strategic supplier partnership, customer relationship, level of information sharing, quality of information sharing and postponement. According to Li et al. (2006), SCM practices impact both performance and competitive advantage of an organisation through price/cost, quality, delivery dependability, time to market, and product innovation. Previous studies have indicated that SCM practices such as strategic supplier partnership can enhance competitive advantage through improving supplier performance and reducing time to market (Ragatz et al., 1997). It has also been observed that practices such as information sharing and information quality contribute positively to customer satisfaction (Spekman et al., 1998). Postponement strategy not only increases the flexibility in the supply chain, but also balances global efficiency and customer responsiveness (Van Hoek et al., 1999). Furthermore, Jie et al. (2013) confirmed the existence of a strong relationship between supply chain practices and competitive advantage. Finally, recent studies have emphasised that SCM practices such as buyer-supplier relationships (Afraz et al., 2021), information sharing (Huo et al., 2021) and customer relationship management (Migdadi, 2021) influence different facets of competitive advantage. This leads to the hypothesis that:

\section{H1. SCM practices positively affect SMEs' competitive advantage.}

\subsection{Logistics capabilities and competitive advantage}

The literature indicates different ways of grouping logistics capabilities (Gligor and Holcomb, 2012). For example, Mentzer et al. (2004) conceptualized logistics capabilities that lead to competitive advantage as being in four broad categories: demand-management capabilities, supply-management capabilities, information-management capabilities and coordination capabilities. Stank et al. (2005) proposed four categories: customer focus, time management, integration, information exchange, and evaluation. Esper et al. (2007) added measurement capabilities. After a systematic literature review, Gligor and Holcomb (2012) concluded on three dimensions of logistics capabilities: demand management capabilities, supply management capabilities and information management capabilities. Researchers have acknowledged that logistics capabilities can be a source of competitive advantage (Gligor and Holcomb, 2014a; Karagoz and Akgun, 2015). According to Cho et al. (2008), a firm with sufficient logistics capabilities is capable of handling small frequent orders, delivering correct orders on-time, communicating shipping information, sharing logistics information with partners, handling returned products, handling global distribution as well as handling and filling orders using web-based systems.

According to Gligor and Holcomb (2012, 2014a), logistics capabilities such as demand management and information management capabilities enable firms differentiate their logistics activities from competitors. Demand management capabilities are customer-focused capabilities that allow the firm to meet specific customers' expectations by providing differentiation through unique value-added activities (Mentzer et al., 2004; Gligor and Holcomb, 2012, 2014a). Information exchange capabilities relate to the firm's ability to analyse, store and distribute strategic and tactical information both internally and externally 
(Zhao et al., 2001; Gligor and Holcomb, 2012). Supply management capabilities involve total system cost minimisation with explicit consideration of cross-functional trade-offs; effective management of time to eliminate wasted capital and inventory; response to demand fluctuations with less distortion of the order cycle process; use of resources to enable postponement speculation, modularization and standardization (Gligor and Holcomb, 2012).

Logistics capabilities, if well managed, can become core competences for a firm geared to achieving competitive advantage and superior performance (Zhao et al., 2001; Mentzer et al., 2004; Cho et al., 2008; Gligor and Holcomb, 2012). Researchers (Mentzer et al., 2004; Gligor and Holcomb, 2014b) argue that as time and quality-based competition becomes intense, the role of logistics capabilities becomes more critical for competitive advantage. Demand chain management logistics capabilities have strong potential to differentiate manufacturing performance and hence create competitive advantage (Frohlich and Westbrook, 2002). It is also recommended that firms should develop the logistics capability of innovativeness, which can act as a catalyst for logistics service differentiation, developing new logistics processes or services in response to a competitors' new offering, resulting into a competitive advantage (Ralston et al., 2013). Finally, recent researchers have also confirmed that logistics capabilities positively influence firms' competitive advantage (Bag et al., 2020; Aziz et al., 2020; Keskin et al., 2021). This leads to the following hypothesis:

H2. Logistics capabilities positively affect SMES' competitive advantage.

\subsection{Supply chain management practices and logistics integration}

Teece $(2014,2018)$ noted that numerous efforts have been devoted to identifying and testing the effects of capabilities but little attention has been drawn towards the need to keep such capabilities integrated. The current escalating competition suggests that firms should improve not only their internal logistics operations but also focus on linking their customers and suppliers in the overall logistics chain (Prajogo and Olhager, 2012). According to Chinomona and Pooe (2013) logistics integration refers to the degree of cooperation, collaboration, interaction and coordination between logistics activities. In circumstances where customer and cost orientations are critical, the capability of integrating activities impact on efficiency and effectiveness of logistics operations (Daugherty et al., 2009; Spillan et al., 2013). Logistics integration can be internal and external: internal logistics integration refers to the competency of a firm to link logistics activities performed internally into a seamless process to support customer requirement (Stank et al., 2002; Paulraj and Chen, 2007). External logistics integration relates to the ability to link logistics activities across firms' boundaries (Paulraj and Chen, 2007). According to the paradigm that suggests competition is at the supply chain level, firms within the supply chain must integrate their specific firm-level logistics capabilities in order to gain a competitive advantage over firms external to the supply chain (Gligor and Holcomb, 2014b).

Gligor and Holcomb (2012) observe that supply chain practices facilitate logistics capabilities and logistics integration. The role of SCM practices such as strategic supplier partnership, customer relationship and information sharing in logistics integration is eminent. For example, literature reveals how it is impossible to achieve integrated logistics capabilities without cooperation at all levels within the firm and among the firms that constitute a supply chain (Heide and Miner, 1992; Gligor and Holcomb, 2012). Similarly internal and external coordination capabilities contribute to process integration and the development of collaborative relationships within the supply chain (Gligor and Holcomb, 2014b). Gligor and Holcomb (2014b) suggest that SCM practices such as cooperation; coordination and communication lead to integrated logistics capabilities. Similarly, Wang et al. (2020) found that supply chain relationships make logistics integration effective. The following hypothesis is therefore stated:

\section{Competitive advantage in SMEs}




\subsection{Logistics capabilities and logistics integration}

Capabilities are composed of a system of interdependent elements which enable strong integration both within and outside the situation (Teece, 2018). Integration of capabilities not only helps in adapting to business environment but also shapes it through response to changes and opportunities (Teece, 2014, 2018). Wiengarten et al. (2014) maintained that with globalisation and cross border transactions, logistics capabilities are reputed for successful integration. Due to the increasing complexity of logistics chains, logistics integration is vital in determining the capabilities that a firm can use to make changes and fully capitalise on opportunities (Chen et al., 2009). Logistics providers with well-developed logistics capabilities can ably ensure proper integration of activities with suppliers/customers (Zacharia et al., 2011; Wiengarten et al., 2014). It is also observed that integration is an integral part of logistics capabilities, especially where information exchange is a concern for routine transactional activities between customers/suppliers and intermediaries (Menzter et al., 2004; Jayaram and Tan, 2010; Gligor and Holcomb, 2012, 2014a). Logistics personnel have the unique capability to actively coordinate with other functions inside the company and to extend logistics externally to incorporate customers and suppliers (Gligor and Holcomb, 2012). This leads to the hypothesis below:

H4. Logistics capabilities positively affect logistics integration in SMEs.

\subsection{Logistics integration and competitive advantage}

Logistics integration with suppliers and customers is important in delivering value to customers and building competitive capabilities like quality, delivery flexibility and cost (Prajogo and Olhager, 2012; Chinomona and Pooe, 2013). For a firm wishing to have a holistic performance in a competitive business environment, different levels of capabilities and processes must be integrated (Teece, 2014, 2018). Teece (2018) argues that proper link between capabilities help in addressing imbalances by ensuring that work flow and information exchange are seamless. Despite the fact that little attention has been given to the relative importance of logistics integration in achieving competitiveness (Mellat-Parast and Spillan, 2013), logistics aspects like internal logistics integration and external logistics integration are deemed to be vital in achieving efficiency and effectiveness in logistics activities (Rodrigues et al., 2004; Gimenez, 2006). In circumstances where customer and cost orientations are paramount, the capability of integrating activities impact on efficiency and effectiveness of logistics operations (Daugherty et al., 2009; Spillan et al., 2013).

Stank et al. (2005) observe that logistics capabilities such as customer focus, time management, integration, information exchange, and evaluation may represent resource expertise in other functional areas. According to the RBV, such firm resources can be a source of competitive advantage (Barney, 1991). Langley and Holcomb (1992) maintained that integrating logistics externally to include customers and suppliers can generate benefits such as asset productivity, operational effectiveness and enhanced customer value. The integration of logistics capabilities is said to be a prerequisite for successful performance in a competitive environment (Bae, 2012; Breznik and Lahovnik, 2016), through lowering overall firm costs, bettering relationships with customers and delivering superior customer value (Gligor and Holcomb, 2012, 2014a). This therefore leads to the fifth hypothesis:

H5. Logistics integration positively affects competitive advantage in SMES.

From the foregoing literature review, it has been observed that SCM practices are positively related to logistics integration (Gligor and Holcomb, 2012, 2014b; Wang et al., 2020). 
Logistics integration is also positively related to competitive advantage in the form of dimensions such as quality, delivery flexibility and cost (Prajogo and Olhager, 2012; Chinomona and Pooe, 2013). In addition, SCM practices are also positively related to competitive advantage (Jie et al., 2013; Afraz et al., 2021; Huo et al., 2021; Migdadi, 2021). For example, Mellat-Parast and Spillan (2014) found that supply chain strategies influence logistics integration, which in turn significantly influences firms' competitive positions. Furthermore, prior research indicates that logistics capabilities are positively related to logistics integration (Zacharia et al., 2011; Gligor and Holcomb, 2012; Wiengarten et al., 2014) and competitive advantage (Gligor and Holcomb, 2012, 2014a; Bag et al., 2020; Aziz et al., 2020; Keskin et al., 2021) (see Figure 1). This discussion leads to the final set of hypotheses:

H6. Logistics integration mediates in the relationship between SCM practices and competitive advantage of SMEs.

H7. Logistics integration mediates in the relationship between logistics capabilities and competitive advantage of SMEs.

\section{Methodology}

\subsection{Design, population and sample}

This research is cross-sectional with the study population comprising of 600 SMEs in Kampala, Uganda (Uganda Small Scale Industries Association, 2019); given that the greater Kampala is the heart of commercial activities in Uganda (UBOS report, 2010/2011). We determined the sample size using Krejcie and Morgan (1970) and generated a sample of 234 SMEs. However, we were able to obtain valid and useful data from 204 SMEs with a response rate of $87.2 \%$.

\subsection{Questionnaire and variable measurement}

A Likert scale questionnaire, designed to measure the opinion or attitude of a respondent was utilised to obtain self-reported information. The questionnaire design was based on previously validated scales. Competitive advantage was measured using dimensions of cost, quality, delivery, innovation and time to market (Li et al., 2006). Logistics capabilities were measured using demand management capabilities and information management capabilities

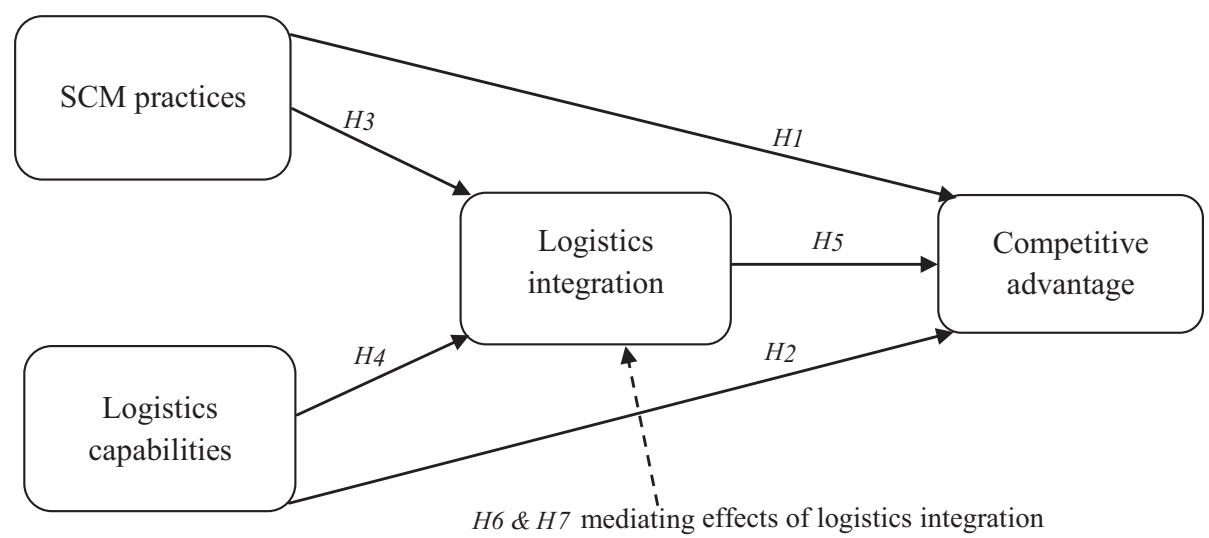

Figure 1. Theoretical model
Competitive advantage in SMEs 
adapted from Gligor and Holcomb (2012, 2014a). SCM practices were measured using strategic supplier partnership, customer relationship, information sharing and postponement (Li et al., 2006). Logistics integration was measured based on dimensions of internal integration and external integration adapted from Rodrigues et al. (2004), Gimenez (2006) and Paulraj and Chen (2007).

\subsection{Tests of factorability, validity and reliability}

We used exploratory factor analysis (EFA) whereby the principal components for each of the five variables were extracted by running principal component analysis using varimax rotation method, and factor loadings below 0.5 were suppressed to avoid extracting factors with weak loadings. We first assessed the suitability of the data for factor analysis based on sample size adequacy, the Kaiser-Meyer-Olkin (KMO) and Bartlett tests. The results indicate that $\mathrm{KMO}$ values were $0.630,0.556,0.529$ and 0.672 for SCM practices, logistics capabilities, logistics integration and competitive advantage respectively. Bartlett's test of sphericity in all scales reached statistical significance $(\phi<0.05)$. We computed content validity index (CVI) by obtaining the proportion of items assessed as useable divided by total number of items (Field, 2009). The CVI was $0.833,0.778,0.889$, and 0.875 for SCM practices, logistics capabilities, logistics integration and competitive advantage respectively. To determine the internal consistency of the measurement scales, we computed Cronbach's alpha coefficients. The standard alpha coefficients were 0.744, 0.726, 0.782 and 0.755 for SCM practices, logistics capabilities, logistics integration and competitive advantage respectively.

From our EFA, the main components of SCM practices were information sharing, strategic supplier partnerships, customer relationships and postponement which all together account for $67.314 \%$ of the variance. Two components of logistics capabilities survived as information management capabilities and demand management capabilities accounting for $72.357 \%$ of the variance in logistics capabilities. Furthermore, internal integration and external integration jointly accounted for $68.866 \%$ of the variance in logistics integration. Finally, time to market, delivery, innovation, quality and cost emerged as the dimensions for competitive advantage jointly accounting for $63.066 \%$ of the variance.

\subsection{Confirmatory factor analysis (CFA)}

In order to confirm the convergent validity of the factors, confirmatory factor analysis (CFA) was performed. In Figure 2, we provide an overview of the measurement model showing the acceptable convergent and discriminant validity. Model fit for both independent and dependent variables are above the recommended cut-off by Hair et al. (2010) for all study variable $\mathrm{CFA}$ measurement model. In particular, Normed Chi-square were above 0.05 , RMSEA below 0.08 , NNFI above 0.95 , CFI above 0.95 and other fit indices met or exceeded the minimum threshold value as per Hair et al. (2010). Moreover, standard loadings were in all cases closer to or greater than 0.50 with considerable high $t$-value $(\phi<0.01)$ and composite reliability values of study factors were all above 0.7 . Therefore, we can conclude that convergent validity exists in our measurement models. Furthermore, discriminant validity was established by comparing the squared correlation between two latent constructs to their average variance extracted (AVE) (Fornell and Larcker, 1981). We established that none of the correlations was higher than the squared root of the AVE for each study variable, further satisfying the existence of discriminant validity.

\section{Empirical findings}

\subsection{Organisational characteristics}

The results revealed that majority of firms were engaged in the trade sector $(34.8 \%)$ followed by accommodation and food services $(33.8 \%)$. The least represented firms in this study 


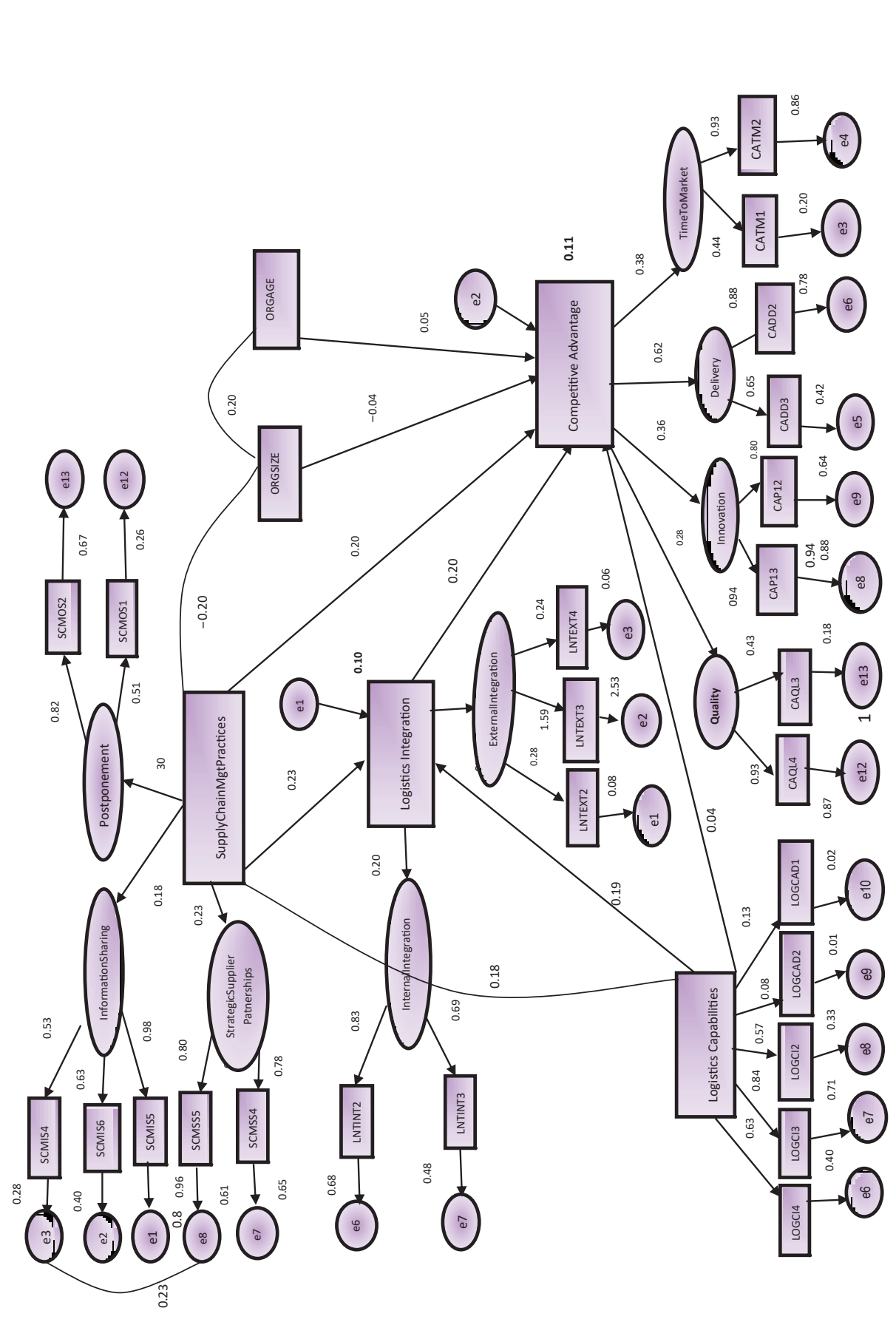

Competitive advantage in SMEs 
included those engaged in other activities than those specified in the questionnaire for instance metal fabrication and carpentry $(2.9 \%)$. Regarding tenure, the majority of SMES were 5-10 years old (42.6\%), followed by those that had existed for a period between 11-15 years constituting $35.8 \%$. The majority (47.5\%) of SMEs operates in the form of sole proprietorship followed by partnerships $(30.4 \%)$ and the least represented category is the private limited company $(22.1 \%)$. Regarding size, results indicate that the majority of firms employ between $5-49$ people $(91.7 \%)$. Those above 50 employees constituted only $8.3 \%$. This implies that the dominant category is the small enterprises. The results also show that the majority $(97.1 \%)$ of SMEs operate on a local basis, while only $2.9 \%$ operate as multinationals.

\subsection{Descriptive statistics and correlations}

From the descriptive analysis, SMEs are rated moderately on the study variables of SCM practices, logistics integration and competitive advantage (Mean $=3.733, \mathrm{SD}=0.513$, Mean $=3.756, \mathrm{SD}=0.454$, Mean $=3.555, \mathrm{SD}=0.696$ ) respectively. Further, we observe that $\mathrm{SMEs}$ need to improve on their logistics capabilities (Mean $=2.838, \mathrm{SD}=0.535$ ). In addition, prior to testing of the study hypothesis, a Pearson $(r)$ correlation was carried out to establish associations among the study variables. This was done because regression analysis assumes linearity, implying that it cannot be carried out on variables that are not related. The correlation results reveal that all the study variables are significantly associated, suggesting that we could proceed to test hypotheses using regression through structural equation modeling.

\subsection{Hypotheses tests results}

In this study, we developed a hypothesized model to identify the underpinning constructs of competitive advantage. To do so, we positioned SCM practices, logistics capabilities as the independent variables, and logistics integration as the mediator variable with competitive advantage as dependent variable. Figure 2 provides the structural model. Model fit was found to be adequate $\left(X^{2}=4.457 \mathrm{DF}=5, \rho=0.49, \mathrm{CMIN} / \mathrm{DF}=0.891, \mathrm{GFI}=0.93, \mathrm{NFI}=0.96\right.$, $\mathrm{RFI}=0.92, \mathrm{IFI}=1.01, \mathrm{TLI}=1.03, \mathrm{CFI}=1.000$, and $\mathrm{RMSEA}=0.000$ ). The results in Table 1 indicate a positive and significant relationship between SCM practices and competitive advantage $(\beta=0.20, \mathrm{CR}=2.86, p=0.004, \mathrm{LB}=0.06, \mathrm{UB}=0.32)$, supporting H1. This implies that when SMEs improve on their SCM practices by, for example, sharing information, developing strategic relationships and implementing postponement strategy, competitive

Table 1. Direct hypotheses results

\begin{tabular}{|c|c|c|c|c|c|c|c|c|}
\hline \multirow[b]{2}{*}{ Hypothesized path } & & & \multirow[b]{2}{*}{$\beta$} & \multirow[b]{2}{*}{$\mathrm{SE}$} & \multirow[b]{2}{*}{$\mathrm{CR}$} & \multicolumn{2}{|c|}{ CI } & \multirow{2}{*}{$\begin{array}{c}p- \\
\text { value }\end{array}$} \\
\hline & & & & & & $\mathrm{LB}$ & UB & \\
\hline Logistics integration & $\leftarrow$ & Logistics capabilities & 0.19 & 0.11 & 1.73 & 0.00 & 0.40 & 0.050 \\
\hline Logistics integration & $\leftarrow$ & SupplyChainMgtPractices & 0.23 & 0.08 & 2.88 & 0.06 & 0.37 & 0.001 \\
\hline $\begin{array}{l}\text { Competitive } \\
\text { advantage }\end{array}$ & $\leftarrow$ & Logistics capabilities & 0.04 & 0.07 & 0.57 & -0.01 & 0.18 & 0.570 \\
\hline $\begin{array}{l}\text { Competitive } \\
\text { advantage }\end{array}$ & $\leftarrow$ & SupplyChainMgtPractices & 0.20 & 0.07 & 2.86 & 0.06 & 0.32 & 0.004 \\
\hline $\begin{array}{l}\text { Competitive } \\
\text { advantage }\end{array}$ & $\leftarrow$ & Logistics integration & 0.20 & 0.06 & 3.33 & 0.07 & 0.31 & 0.002 \\
\hline $\begin{array}{l}\text { Competitive } \\
\text { advantage }\end{array}$ & $\leftarrow$ & ORGSIZE & -0.04 & 0.07 & -0.57 & -0.18 & 0.09 & 0.510 \\
\hline $\begin{array}{l}\text { Competitive } \\
\text { advantage }\end{array}$ & $\leftarrow$ & ORGAGE & 0.05 & 0.07 & 0.71 & -0.08 & 0.18 & 0.475 \\
\hline \multicolumn{9}{|c|}{ Source(s): SEM analysis } \\
\hline
\end{tabular}


advantage is likely to improve. Also, the study finds a positive and significant relationship between logistics integration and competitive advantage $(\beta=0.20, \mathrm{CR}=3.33, p=0.002$, $\mathrm{LB}=0.07, \mathrm{UB}=0.31$ ), thereby substantiating H5. This implies that when SMEs integrate their logistics operations at firm level as well as upstream with suppliers and downstream with customers, they are likely to achieve superior advantage over their competitors. Additionally, a positive and significant relationship was also observed between SCM practices and logistics integration $(\beta=0.23, \mathrm{CR}=2.88, p=0.01, \mathrm{LB}=0.06, \mathrm{UB}=0.37)$ and this supports H3. This particularly implies that when SMEs improve on their SCM practices, they are likely to increase external and internal integration of their logistics activities. Further, the results indicated a positive and significant association between logistics capabilities and logistics integration $(\beta=0.19, \mathrm{CR}=1.73, p=0.050, \mathrm{LB}=0.00, \mathrm{UB}=0.40)$, supporting H4. This finding implies that when SMEs implement strategies that increase their demand management and information management capabilities, they are likely to achieve increased logistics integration. Lastly, the study finds a positive but non-significant association between logistics capabilities and competitive advantage $(\beta=0.04, \mathrm{CR}=0.57$, $p=0.570, \mathrm{LB}=-0.01, \mathrm{UB}=0.18$ ), thereby not supporting H2. This implies that when SMEs improve on their demand management and information management capabilities, they are not likely to achieve improved competitive advantage. Finally, we did not find significant relationships among control variables - organisational size and age with competitive advantage amongst SMEs. The SEM regression results show that together, SCM practices, logistics capabilities and logistics integration account for a variation of $11 \%$ in competitive advantage $(\mathrm{SMC}=0.11)$.

\subsection{Mediation testing}

In order to test for the mediation relationship posited in $\mathrm{H} 6$ and $\mathrm{H} 7$, a bootstrapping technique (Hayes and Scharkow, 2013) was used. In order to test the hypotheses, the indirect effect coefficients were generated using 5,000 bootstrap samples, along with a 95\% biased corrected confidence interval. Results in Table 2 , show that logistics integration significantly mediates between logistics capabilities, SCM practices and competitive advantage $\beta=0.038$, $p<0.05, \mathrm{LB}=0.001, \mathrm{UB}=0.102 ; \beta=0.044, p<0.05, \mathrm{LB}=0.009, \mathrm{UB}=0.100$ ) respectively. These mediation results indicate that logistics integration partially mediates between SCM practices and competitive advantage, logistics capabilities and competitive advantage (variance accounted for $(\mathrm{VAF})=18 \%, 46 \%$ ). The partial mediation conclusion is due to the fact that the variance accounted for (VAF) for each of the indirect paths is less than $80 \%$.

\section{Discussion}

The results reported in this paper suggest that SCM practices significantly predict competitive advantage. This implies, for example, that SMEs that keep each other informed about events or changes that may affect their trading partners, and are able to exchange accurate information with their trading partners are likely to achieve advantages over competitors. The finding further implies that strengthening relationships with suppliers and customers as well as implementing postponement strategies and designing products/services according to customer needs can enable SMEs achieve competitive advantage. This finding is consistent with previous scholars such as Li et al. (2006) who argue that SCM practices improve competitive advantage through price/cost, quality, delivery dependability, time to market, and product innovation. It is argued that strategic supplier partnership can improve supplier performance and reduce time to market (Ragatz et al., 1997), information sharing and information quality contribute positively to customer satisfaction (Spekman et al., 1998) and postponement strategy not only increases flexibility in the supply chain, but also balances global efficiency and customer responsiveness (Van Hoek et al., 1999). Similarly, recent
Competitive advantage in SMEs 
JBSED

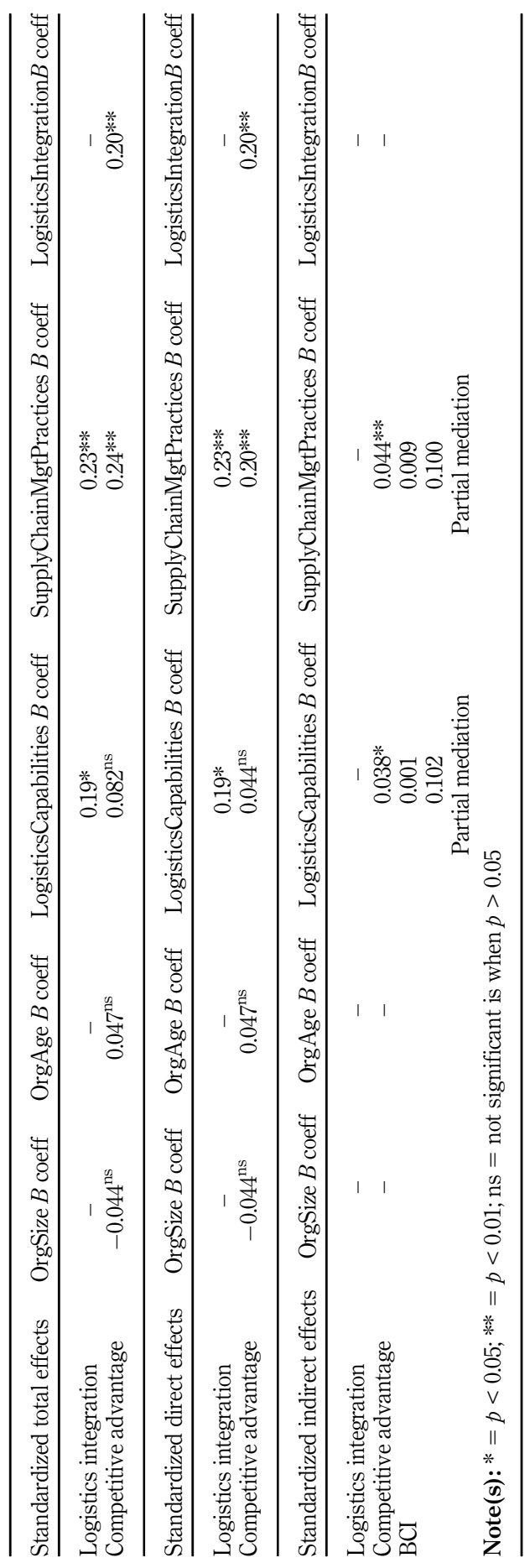

Table 2.

Mediation results 
studies have emphasised that SCM practices such as buyer-supplier relationships (Afraz et al., 2021), information sharing (Huo et al., 2021) and customer relationship management (Migdadi, 2021) influence different dimensions of SCM practices. In this study, it is noticeable that the postponement dimension had the lowest contribution to SCM practices compared to other dimensions as it accounted for the lowest variation. This could perhaps be explained by the context of this study where more than $80 \%$ of SMEs operate in the trade sector, accommodation, food services, recreation and personal services. This makes postponement more difficult than for example in the case of manufacturing where raw materials and components can be stored pending customer orders.

The study established a positive but non-significant relationship between logistics capabilities and competitive advantage. This analysis reveals that logistics capabilities do not significantly predict competitive advantage. This therefore means that for SMEs in Uganda, possession of demand management and information management capabilities does not cause a significant variation in competitive advantage. It implies for example that SMEs' linkages and synchronisation of information and logistics operations with customers may not cause a significant variation in their competitive advantage. These findings contradict previous studies (e.g. Mentzer et al., 2004; Gligor and Holcomb, 2014a) who underlined the critical role of logistics capabilities in enhancing competitiveness. More generally, it is argued that logistics capabilities, if well managed, can become core competences for a firm geared to achieving competitive advantage and superior performance (Cho et al., 2008; Gligor and Holcomb, 2012; Ralston et al., 2013). In the same line, recent studies have underlined that logistics capabilities positively influence firms' competitive advantage (Bag et al., 2020; Aziz et al., 2020; Keskin et al., 2021). This contradictory finding may be attributed to the context of SMEs in developing countries and Uganda in particular, where it is reported that logistics capabilities and logistics performance are generally deficient (World Bank report, 2017; Langley and Infosys, 2018). Furthermore, SMEs in developing countries (e.g. Uganda) are known to be resource constrained, which makes it difficult to develop adequate logistics capabilities due to infrastructure and technology deficiencies.

The findings further revealed a positive and significant relationship between SCM practices and logistics integration. This suggests that when SMEs improve their SCM practices for example by exchanging accurate information and strengthening relationships with their supply chain partners, they are likely to achieve increased internal and external integration of their logistics operations. This is in line with previous scholars such as Jarrell et al. (1998) who contend that information sharing as a SCM practice leads to high levels of supply chain integration. Similarly, Gligor and Holcomb (2012) and Gligor and Holcomb (2014a) argued that supply chain practices facilitate logistics capabilities and logistics integration across the supply chain. Furthermore, we found a positive and significant relationship between logistics capabilities and logistics integration. This suggests that SMEs that improve on information management and demand management capabilities are likely to achieve greater internal and external integration of their logistics activities. These findings concur with previous research which affirms that firms with well-developed logistics capabilities can ensure proper integration of activities with suppliers/customers (Zacharia et al., 2011; Wiengarten et al., 2014). This also agrees with Wang et al. (2020) who argued that supply chain relationships make logistics integration effective.

Finally, we found a significant and positive relationship between logistics integration and competitive advantage. This implies that when SMEs integrate their logistics operations internally and with their suppliers and customers, they are likely to achieve superior advantage over their competitors. These findings confirm those of previous researchers (e.g. Prajogo and Olhager, 2012; Chinomona and Pooe, 2013), which emphasise that logistics integration with suppliers and customers is important in delivering value to customers and building competitive capabilities like quality, delivery flexibility and cost minimisation.
Competitive advantage in SMEs 


\section{Summary and conclusions}

The study sought to investigate the antecedents of competitive advantage in SMEs from a logistics and SCM perspective. Based on the extant literature and guided by the RBV and dynamic capabilities theoretical perspectives, SCM practices, logistics capabilities and logistics integration were theorised as potential antecedents of competitive advantage of SMEs. Indeed, the findings revealed positive and significant relationships between SCM practices and competitive advantage; SCM practices and logistics integration; logistics capabilities and logistics integration; logistics integration and competitive advantage. It was only with logistics capabilities that we found a non-significant relationship with competitive advantage. We also found that SCM practices, logistics capabilities and logistics integration predict up to $11 \%$ of competitive advantage.

This study has implications for both theory and practice. Theoretically, we invoke the RBV and dynamic capabilities perspectives of competitive advantage in SMEs. In so doing, we clarify on the relationship between SCM practices, logistics capabilities, logistics integration and competitive advantage. In practice, SMEs wishing to improve their competitive positions should share strategic information that can help them and their supply chain partners in planning and forecasting so as to be proactive in their operations. SMEs should also share information concerning any changes that might affect their trading partners, for example, concerning new product/service development and other business processes. The information shared should be timely, complete and accurate but they should first assess the willingness of their trading partners to reciprocate to avoid the cost of divulging valuable information without corresponding return, which may be counterproductive to their competitiveness.

Second, SMEs should build strategic supplier partnerships in aspects such as sharing continuous improvement programs with key suppliers and including key suppliers in their planning and goal-setting activities. SMEs should also encourage integration of their logistics operations at firm level and with their suppliers and customers. Thus they should embrace information technology in fostering logistics integration for example by establishing data management architectures such as data bases for sharing data, installing software services like ERP and ensuring compliance with new technological trends.

In addition, logistics capabilities did not significantly predict competitive advantage and this could perhaps be due to resource constraints that characterise SMEs in Uganda and elsewhere in the world, which makes it difficult to build logistics capabilities. Hence, government support is important for improving SMEs' competitiveness through financial assistance, construction of logistics infrastructure such transport and communication networks that can help in logistics integration and improve SCM practices such as information sharing. It is well acknowledged that public procurement constitutes a significant proportion of government spend. Hence the government should support SMEs' participation in public procurement, for example by offering preferential treatment so as to boost their market share and cash inflows.

Finally, we acknowledge some limitations in this study, some of which signal avenues for further research. For example, this study used a survey based design using close ended questions that would limit additional explanations and in-depth information. Future research could use methods that provide more detailed information about the study variables such as qualitative case studies using in-depth-interviews. Furthermore, the study was crosssectional, which limits observation of behaviour with lapse of time. Behavioural practices like strategic supplier partnerships and information sharing behaviour can change overtime. Future studies could adopt a longitudinal design to observe the behaviour of such variables so as to counteract this limitation. Furthermore, this study was limited to SMEs in Uganda, and specifically in the greater Kampala area. Besides potential limited generalisability to the entire Ugandan SMEs, the findings may not be generalisable to all SMEs in developing 
countries. Future studies can use a larger geographical area in Uganda as well as other countries for purposes of external validity.

\section{References}

Afraza, M., Bhattia, S., Ferraris, A. and Couturier, J. (2021), "The impact of supply chain innovation on competitive advantage in the construction industry: evidence from a moderated multimediation model", Technological Forecasting and Social Change, Vol. 162, doi: 10.1016/j.techfore. 2020.120370 .

Ali, I. and Gölgeci, I. (2019), "Where is supply chain resilience research heading? A systematic and cooccurrence analysis", International Journal of Physical Distribution and Logistics Management, Vol. 49 No. 8, pp. 793-815.

Arsawan, E., Koval, V., Rajiani, I., Rustiarini, W., Supartha, W. and Suryantini, S. (2020), "Leveraging knowledge sharing and innovation culture into SMEs sustainable competitive advantage", International Journal of Productivity and Performance Management. doi: 10.1108/IJPPM-042020-0192.

Aziz, A., Memon, A. and Ali, S. (2020), "Logistics capability, logistics outsourcing and firm performance in manufacturing companies in Pakistan", Journal of Asian Finance, Economics and Business, Vol. 7 No. 8, pp. 435-444.

Bae, H. (2012), "The influencing factors of logistics integration and customer service performance for value creation of port logistic s firms", The Asian Journal of Shipping and Logistics, Vol. 28 No. 3, pp. 345-368.

Bag, S., Gupta, S. and Luo, Z. (2020), "Examining the role of logistics 4.0 enabled dynamic capabilities on firm performance", The International Journal of Logistics Management, Vol. 31 No. 3, pp. 607-628.

Barney, J. (1991), "Firm resources and sustained competitive advantage", Journal of Management, Vol. 17 No. 1, pp. 99-120.

Brandon-Jones, E., Squire, B., Autry, C. and Petersen, K. (2014), "A contingent resource-based perspective of supply chain resilience and robustness", Journal of Supply Chain Management, Vol. 50 No. 3, pp. 55-73.

Breznik, L. and Lahovnik, M. (2016), "Dynamic capabilities and competitive advantages: findings from case studies", Management Journal of Contemporary Management Issues, Vol. 21 Special Issue, pp. 167-185.

Chang, C., Lu, C. and Lai, P. (2021), "Examining the drivers of competitive advantage of the international logistics industry", International Journal of Logistics Research and Applications. doi: 10.1080/13675567.2021.1915263.

Chen, H., Daugherty, P.J. and Landry, T.D. (2009), "Supply chain process integration: a theoretical framework", Journal of Business Logistics, Vol. 30 No. 2, pp. 27-46.

Chinomona, R. and Pooe, R. (2013), "The influence of logistics integration on information sharing and business performance: the case of small and medium enterprises in South Africa", Journal of Transport and Supply Chain Management, Vol. 7 No. 1, pp. 92-101.

Cho, J.K.J., Ozment, J. and Sink, H. (2008), "Logistics capability, logistics Outsourcing and Firm Performance in an e-commerce market", International Journal of Physical Distribution and Logistics Management, Vol. 38 No. 5, pp. 336-359.

Daugherty, J.P., Chen, H., Mattioda, D.D. and Grawe, J.S. (2009), "Marketing/logistics relationships: influence on capabilities and performance", Journal of Business Logistics, Vol. 30 No. 1, pp. 1-18.

Day, M., Lichtenstein, S. and Samouel, P. (2015), "Supply management capabilities, routine bundles and their impact on firm performance", International Journal of Production Economics, Vol. 164, pp. 1-13.

Esper, T.L., Fugate, B.S. and Davis-Sramek, B. (2007), "Logistics learning capability: sustaining the competitive advantage gained through logistics leverage", Journal of Business Logistics, Vol. 28 No. 2, pp. 57-82.
Competitive advantage in SMEs

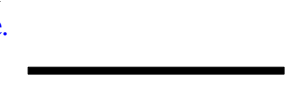


Eyaa, S. and Ntayi, J. (2010), "Procurement practices and supply chain performance of SMEs in Kampala", Asian Journal of Business Management, Vol. 2 No. 4, pp. 82-88.

Field, A. (2009), Discovering Statistics Using SPSS, 3rd ed., Sage Publications, London.

Fornell, C. and Larcker, D.F. (1981), "Evaluating structural equation models with unobservable variables and measurement error", Journal of Marketing Research, Vol. 18 No. 1, pp. 39-50.

Frohlich, M.T. and Westbrook, R. (2002), "Demand chain management in manufacturing and services: web-based integration, drivers and performance", Journal of Operations Management, Vol. 20 No. 6, pp. 729-745.

Gimenez, C. (2006), "Logistics integration processes in the food industry", International Journal of Physical Distribution and Logistics Management, Vol. 36 No. 3, pp. 231-249.

Gligor, D.M. and Holcomb, M.C. (2012), "Understanding the role of logistics capabilities in achieving supply chain agility: a systematic literature review", Supply Chain Management: An International Journal, Vol. 17 No. 4, pp. 438-453.

Gligor, D.M. and Holcomb, M. (2014a), "The road to supply chain agility: an RBV perspective on the role of logistics capabilities", The International Journal of Logistics Management, Vol. 25 No. 1, pp. 160-179.

Gligor, M. and Holcomb, M. (2014b), "Antecedents and consequences of integrating logistics capabilities across the supply chain”, Transportation Journal, Vol. 3 No. 2, pp. 211-234.

Hair, F., Black, C., Babin, J. and Anderson, E. (2010), Multivariate Data Analysis, 7th ed., Prentice-Hall, Upper Saddle River, New Jersey.

Hayes, A. and Scharkow, M. (2013), "The relative trustworthiness of inferential tests of the indirect effect in statistical mediation analysis: does method really matter?", Psychological Science, Vol. 24 No. 10, pp. 1918-1927.

Heide, J.B. and Miner, A.S. (1992), "The shadow of the future: effects of anticipated interaction and frequency of contact on buyer-seller cooperation”, Academy of Management Journal, Vol. 35 No. 2, pp. 265-291.

Huo, B., Haq, M. and Gu, M. (2021), “The impact of information sharing on supply chain learning and flexibility performance", International Journal of Production Research, Vol. 59 No. 5, pp. 1411-1434, doi: 10.1080/00207543.2020.1824082.

Jarrell, J.L. (1998), Supply Chain Economics, World Trade, Vol. 11 No. 11, pp. 58-61.55.

Jayaram, J. and Tan, K.C. (2010), "Supply chain integration with third-party logistics providers", International Journal of Production Economics, Vol. 125 No. 2, pp. 262-271.

JICA report (2017), "Japan international cooperation agency project for master plan on Logistics in Northern Economic Corridor", Kenya and Uganda, Final report, available at: https:// openjicareport.jica.go.jp/pdf/12291779_01.pdf.

Jie, F., Parton, K.A. and Cox, R.J. (2013), "Linking supply chain practices to competitive advantage: an example from Australian agribusiness", British Food Journal, Vol. 115 No. 7, pp. 1003-1024.

Karagöz, B. and Akgün, E.A. (2015), "The roles of IT capability and organizational culture on logistics capability and firm performance”, Journal of Business Studies Quarterly, Vol. 7 No. 2, pp. 1-23.

Keskin, H., Ayar Şentürk, H., Tatoglu, E., Gölgeci, I., Kalaycioglu, O. and Etlioglu, H.T. (2021), “The simultaneous effect of firm capabilities and competitive strategies on export performance: the role of competitive advantages and competitive intensity", International Marketing Review. doi: 10.1108/IMR-09-2019-0227.

Koh, S., Demirbag, M., Bayraktar, E., Tatoglu, E. and Zaim, S. (2007), "The impact of supply chain management practices on performance of SMEs", Industrial Management and Data Systems, Vol. 107 No. 1, pp. 103-124.

Koufteros, X.A., Vonderembse, M.A. and Doll, J. (1997), “Competitive capabilities: measurement and relationships”, Proceedings Decision Science Institute, Vol. 3 No. 1, pp. 1067-1068. 
Krejcie, P. and Morgan, D.W. (1970), "Determining sample size for research activities”, Educational and Psychological Measurement, Vol. 30 No. 3, pp. 607-610.

Kwak, D., Seo, Y. and Mason, R. (2018), "Investigating the relationship between supply chain innovation, risk management capabilities and competitive advantage in global supply chains", International Journal of Operations and Production Management, Vol. 38 No. 1, pp. 211-229.

Langley, J. and Capegmini (2017), "Third-Part Logistics srudy; the state of logistics outsourcing”, The 21st Annual Third-Party Logistics Study, Capgemini Consulting, Pennstate.

Langley, C.J. and Holcomb, M.C. (1992), "Creating logistics customer value”, Journal of Business Logistics, Vol. 13 No. 2, pp. 1-27.

Langley, C.J. and Infosys, (2018), “Third-Party logistics study”, The State of Logistics outsourcing; Results and findings of the 22nd Annual Study.

Li, S., Ragu-Nathan, B., Ragu-Nathan, T.S. and Rao, S.S. (2006), "The impact of supply chain management practices on competitive advantage and organizational performance", International Journal of Management Science, Omega, Vol. 34 No. 2, pp. 107-124.

McGinnis, M.A. and Vallopra, R.M. (1999), "Purchasing and supplier involvement in process improvement: a source of competitive advantage", Journal of Supply Chain Management, Vol. 35 No. 4, pp. 42-50.

McGinnis, M.A., Kohn, J.W. and Spillan, J.E. (2010), “A longitudinal study of logistics strategy: 19902008”, Journal of Business Logistics, Vol. 31 No. 1, pp. 217-235.

Mellat-Parast, M. and Spillan, E.J. (2014), "Logistics and supply chain process integration as a source of competitive advantage”, The International Journal of Logistics Management, Vol. 25 No. 2, pp. 289-314.

Mentzer, J.T., Min, S. and Bobbitt, L.M. (2004), "Toward a unified theory of logistics", International Journal of Physical Distribution and Logistics Management, Vol. 34 No. 8, pp. 606-627.

Migdadi, M. (2021), "Knowledge management, customer relationship management and innovation capabilities", Journal of Business and Industrial Marketing, Vol. 36 No. 1, pp. 111-124.

Min, S. and Mentzer, J. (2004), "Developing and measuring supply chain concepts", Journal of Business Logistics, Vol. 25 No. 1, pp. 63-99.

Ministry of Finance, Planning and Economic Development (MFPED) report (2008), Government of Uganda, available at: https://www.finance.go.ug.

Morash, E.A., Droge, C.L.M. and Vickery, S. (1996), "Strategic logistics capabilities for competitive advantage and firm success", Journal of Business Logistics, Vol. 17 No. 1, pp. 1-22.

National survey of small businesses in Uganda (2015), Financial sector deepening (FSD) Uganda, available at: https://fsduganda.or.ug/uganda-national-small-business-survey-report/.

Paulraj, A. and Chen, I.J. (2007), "Strategic buyer-supplier relationships, information technology and external logistics integration”, Journal of Supply Chain Management, Vol. 43 No. 2, pp. 2-14.

Porter, M.E. (1985), Competitive Advantage: Creating and Sustaining Superior Performance, Free Press, New York, NY.

Prajogo, D. and Olharger, J. (2012), "Supply chain integration and performance: the effects of longterm relationships, information technology and sharing, and logistics integration", International Journal of Production Economics, Vol. 135 No. 1, pp. 514-522.

Private Sector Foundation Uganda (2006), available at: https://www.psfuganda.org/.

Ragatz, G.L., Handfield, R.B. and Scannell, T.V. (1997), "Success factors for integrating suppliers into new product development", Journal of Product Innovation Management, Vol. 14 No. 3, pp. 190-202.

Ralston, P.M., Grawe, S.J. and Daugherty, P.J. (2013), "Logistics salience impact on logistics capabilities and performance", The International Journal of Logistics Management, Vol. 24 No. 2, pp. 136-152.
Competitive advantage in SMEs

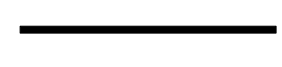


Rodrigues, A.M., Stank, T.P. and Lynch, D.F. (2004), "Linking strategy, structure, process, and performance in integrated logistics", Journal of Business Logistics, Vol. 25 No. 2, pp. 65-94.

Sandberg, E. and Abrahamsson, M. (2011), "Logistics capabilities for sustainable competitive advantage", International Journal of Logistics Research and Applications: A Leading Journal of Supply Chain Management, Vol. 14 No. 1, pp. 61-75.

Sanders, N., Autry, W. and Gligor, M. (2011), "The impact of buyer firm information connectivity enablers on supplier firm performance-a relational view", International Journal of Logistics Management, Vol. 22 No. 2, pp. 179-201.

Spekman, R.E., Kamauff, J.W. and Myhr, N. (1998), "An empirical investigation into supply chain management: a perspective on partnerships", Supply Chain Management. An International Journal, Vol. 3 No. 2, pp. 53-67.

Spillan, J.E., McGinnis, M.A., Kara, A. and Liu Yi, G. (2013), "A comparison of the effect of logistic strategy and logistics integration on firm competitiveness in the USA and China", The International Journal of Logistics Management, Vol. 24 No. 2, pp. 153-179.

Stank, P.T., Keller, B.S. and Closs, J.D. (2002), "Performance benefits of supply chain", Logistical Integration Transportation, Journal, Vol. 41 Nos 2-3, pp. 32-46.

Stank, T.P., David, B.R. and Fugate, B.S. (2005), "A strategic framework for supply chain oriented logistics”, Journal of Business Logistics, Vol. 26 No. 2, pp. 27-45.

Stank, T. and Lackey, W. (1997), "Enhancing performance through logistical capabilities in Mexican maquiladora firms", Journal of Business Logistics, Vol. 18 No. 1, pp. 91-123.

Sullivan-Taylor, B. and Branicki, L. (2011), "Creating resilient SMEs: why one size might not fit all", International Journal of Production Research, Vol. 49 No. 18, pp. 5565-5579.

Tan, K., Kannan, V. and Handfield, R. (1998), "Supply chain management: supplier performance and firm performance", International Journal of Purchasing and Materials Management, Vol. 34 No. 3, pp. 2-9.

Tan, K.C., Lyman, S.B. and Wisner, J. (2002), "Supply chain management: a strategic perspective", International Journal of Operations and Production Management, Vol. 22 No. 6, pp. 614-631.

Teece, D.J. (2014), "A dynamic capabilities-based entrepreneurial theory of the multinational enterprise", Journal of International Business Studies, Vol. 45, pp. 8-37.

Teece, D.J. (2018), "Dynamic capabilities as (workable) management systems theory", Journal of Management and Organization, Vol. 24 No. 3, pp. 359-368, doi: 10.1017/jmo.2017.75.

Teece, D.J., Pisano, G. and Shuen, A. (1997), "Dynamic capabilities and strategic management", Strategic Management Journal, Vol. 18 No. 7, pp. 509-533.

Thun, J., Drüke, M.M. and Hoenig, D. (2011), "Managing uncertainty - an empirical analysis of supply chain risk management in small and medium sized enterprises", International Journal of Production Research, Vol. 49 No. 18, pp. 5511-5525.

Uganda Bureau of Statistics report (2003), Report on socio-economic survey, available at: https://www. ubos.org/wp-content/uploads/publications/03_2018unhs_200203_report.PDF.

Uganda Bureau of Statistics report (2010/2011), Census of Business Establishments in Uganda, Uganda Bureau of Statistics (UBoS), Kampala.

Uganda small scale industries association (2019), available at: ussiauganda.tripod.com (accessed 30 September 2019).

Van Hoek, R.I. and Voss, I. (1999), "Commandeur HR. Restructuring European supply chain by implementing postponement strategies", Long Range Planning, Vol. 32 No. 5, pp. 505-518.

Wang, Q., Huo, B. and Zhao, X. (2020), "What makes logistics integration more effective? Governance from contractual and relational perspectives", Journal of Business Logistics, Vol. 41 No. 3, pp. 259-281, doi: 10.1111/jbl.12236. 
Wedawatta, G., Ingirige, B. and Amaratunga, D. (2010), "Building up resilience of construction sector SMEs and their supply chains to extreme weather events", International Journal of Strategic Property Management, Vol. 14 No. 4, pp. 362-375.

Wiengarten, F., Pagell, M., Ahmed, M.U. and Gimenez, C. (2014), "Do a country's logistical capabilities moderate the external integration performance relationship?", Journal of Operations Management, Vol. 32 Nos 1-2, pp. 51-63.

World Bank report (2017), Skills to Support the Transport and Logistics Sector; Toward Productive, Efficient and Competitive Transport and Logistics Sector in Uganda, Washington, DC, available at: https://openknowledge.worldbank.org/handle/10986/28945.

Zacharia, G., Sanders, R. and Nix, W. (2011), "The emerging role of the third-party logistics provider (3PL) as an orchestrator", Journal of Business Logistics, Vol. 32 No. 1, pp. 40-54.

Zhao, M., DrÖge, C. and Stank, P. (2001), "The effects of logistics capabilities on firm performance: customer-focused versus information-focused capabilities", Journal of Business Logistics, Vol. 22 No. 2, pp. 91-107.

\section{Corresponding author}

Benjamin Tukamuhabwa can be contacted at: btukamuhabwa@mubs.ac.ug

For instructions on how to order reprints of this article, please visit our website:

www.emeraldgrouppublishing.com/licensing/reprints.htm

Or contact us for further details: permissions@emeraldinsight.com 